\title{
Advances of Cancer Therapy by Nanotechnology
}

Xu Wang, Ph.D.'

Yiqing Wang, Ph.D. ${ }^{2}$

Zhuo (Georgia) Chen, Ph.D.'

Dong M. Shin, M.D.

${ }^{1}$ Department of Hematology and Medical Oncology, Winship Cancer Institute and ${ }^{2}$ Department of Biomedical Engineering, Emory University School of Medicine, Atlanta, GA, USA
Recent developments in nanotechnology offer researchers opportunities to significantly transform cancer therapeutics. This technology has enabled the manipulation of the biological and physicochemical properties of nanomaterials to facilitate more efficient drug targeting and delivery. Clinical investigations suggest that therapeutic nanoparticles can enhance efficacy and reduced side effects compared with conventional cancer therapeutic drugs. Encouraged by rapid and promising progress in cancer nanotechnology, researchers continue to develop novel and efficacious nanoparticles for drug delivery. The use of therapeutic nanoparticles as unique drug delivery systems will be a significant addition to current cancer therapeutics.

Correspondence: Dong M. Shin, M.D.

Department of Hematology and Medical

Oncology, Winship Cancer Institute, Emory

University School of Medicine, 1365 Clifton Rd.

Building C. Room C3094. Atlanta, GA 30322, USA

Tel: $1-404-778-2980$

Fax: 1-404-778-5520

E-mail: dmshin@emory.edu

This work was supported by National Cancer Institute (NCI) Specialized Program of Research Excellence (SPORE) grant (P50CA128613) to D.M. Shin and Centers of Cancer Nanotechnology Excellence (CCNE) grant (U54 CA119338) to D.M. Shin and Z.G. Chen.

\author{
Key words \\ Nanoparticels, Cancer therapy, Drug delivery
}

\section{Introduction}

Conventional chemotherapeutic drugs are distributed nonspecifically in the body where they affect both cancerous and healthy cells, resulting in dose-related side effects and inadequate drug concentrations reaching the tumor. Non-specific drug delivery leads to significant complications that represent a serious obstacle to effective anticancer therapy. In addition, the occurrence of resistance phenomena reduces the efficacy of cancer treatment. To overcome the lack of specificity of conventional chemotherapeutic drugs, several ligand-targeted therapeutic strategies, including immunotoxins, radioimmunotherapeutics, and drug immunoconjugates, are being developed. Although these conjugated agents have shown promising efficacy compared with conventional chemotherapy drugs, limitations in their delivery efficiency still remain.

Recent progress in cancer nanotechnology raises exciting opportunities for specific drug delivery. Nanoparticles, particularly in the size range from $10 \mathrm{~nm}$ to $100 \mathrm{~nm}$, are emerging as a class of therapeutics for cancer treatment. Nanoparticles can be composed of several functional molecules simultaneously, such as small molecule drugs, peptides, proteins, and nucleic acids. By using both passive and active targeting strategies, nanoparticles can increase the intracellular concentration of drugs in cancer cells while minimizing toxicity in normal cells; thereby enhancing anticancer effects and reducing systemic toxicity simultaneously, when compared with the therapeutic entities they contain. Furthermore, nanoparticles offer 
the potential to overcome drug resistance, since nanoparticles can bypass the P-glycoprotein efflux pump, one of the main drug resistance mechanisms, leading to greater intracellular accumulation.

The purpose of this review article is to summarize the results of the use of therapeutic nanoparticles in the clinic and discuss the opportunities and challenges faced by therapeutic nanoparticles. Thus, the first part will emphasize the key properties of therapeutic nanoparticles and how these properties affect the efficiency and specificity of nanoparticles as a drug delivery system. Next, we will summarize current clinical uses of the first-generation therapeutic nanoparticles and the advances in new generation of therapeutic nanoparticles currently under preclinical and clinical investigation. Finally, we will discuss how nanoparticles will be developed to improve their therapeutic efficacy and function for future cancer treatment.

\section{Nanoparticles for Tumor Targeting and Delivery}

Nanoparticles used for anticancer drug delivery can be made from a variety of materials, including polymers, dendrimers, liposomes, viruses, carbon nanotubes, and metals such as iron oxide and gold (Fig. 1). So far, almost all the nanoparticle delivery systems which have been approved by the FDA or are currently in clinic trials are based on polymers or liposomes (1).

\section{Polymeric nanoparticles}

Generally, polymers that are used for preparation of nanoparticles fall into two major categories: natural polymers and synthetic polymers. A number of natural polymers such as heparin, dextran, albumin, gelatine, alginate, collagen, and chitosan have been intensively investigated. Synthetic polymers including polyethylene glycol (PEG), polyglutamic acid (PGA), polylactic acid (PLA), polycarprolactone (PCL) and N-(2-hydroxypropyl)-methacrylamide copolymer (HPMA) have been exploited as well. General requirements for those polymers are biocompatibility, biodegradability, and their capacity to be functionalized (2).

The formation of polymeric nanoparticles has been summarized by several review articles $(3,4)$. In most cases, the polymeric nanoparticle consists of two parts, a hydrophobic core which serves as the container for anticancer agents and a hydrophilic shell which stabilizes the nanoparticle in aqueous environments.

The drug can be loaded into polymeric nanoparticles through two methods: by physical entrapment or by chemical conjugation. A hydrophobic interaction between the core of the polymeric nanoparticle and the drug molecule allow the drug to be entrapped in the nanoparticle core. For instance, deoxychilic acid-modified

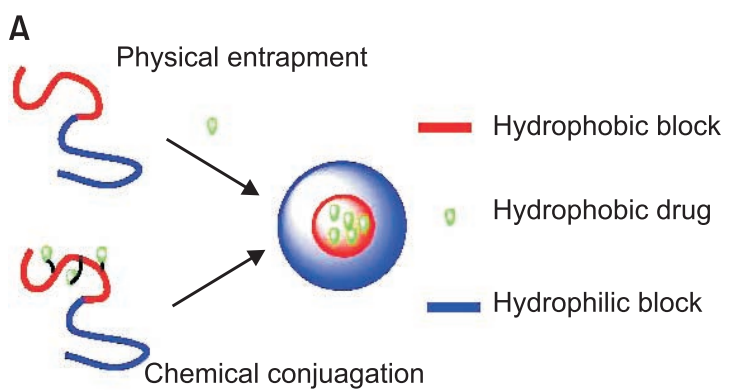

B

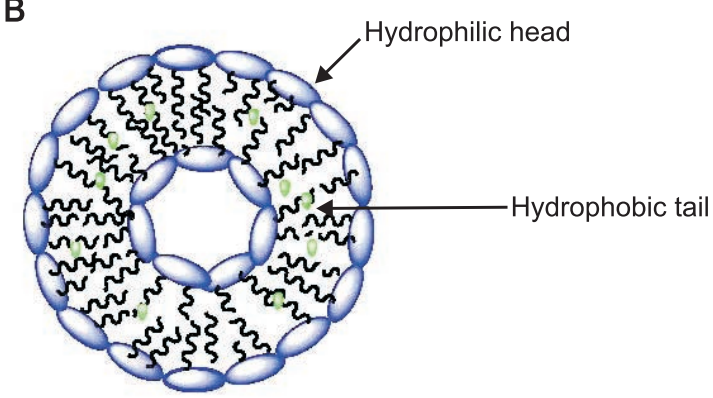

C

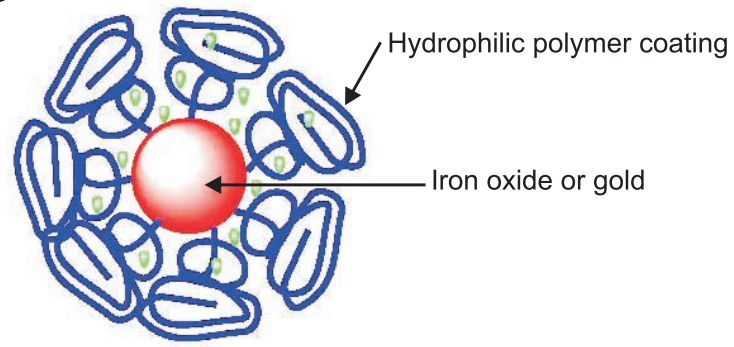

Fig. 1. Illustration of (A) polymer based nanoparticles; (B). Liposome based nanoparticles; and (C). Iron oxide or gold nanoparticles.

heparin can self-assemble into 100 200 nm nanoparticles (5) and its hydrophobic core can be used to entrap $4 \sim 12 \%$ of the total weight of doxorubicin (6) When the drug molecule is covalently conjugated onto the polymer, the chemical properties of the linker between the drug and polymer are critical. If the linker is too stable, drug release may be delayed, while if the linker is too unstable, drug may be released before the nanoparticle reaches the tumor. Therefore, a proper linker is very important to the drug-polymer conjugate. A variety of $\mathrm{pH}$-sensitive linkers have been developed such as hydrozone and cis-aconityl $(7,8)$. These chemical bonds are stable in the blood circulation system $(\mathrm{pH}=7)$, but quickly decompose and release drug molecules inside the tumor where $\mathrm{pH}$ values typically drop below 5.5. Disulfide bonds are also very attractive because they can be cleaved by glutathione. The intracellular level of glutathione is much higher than its extracellular level, therefore, the disulfide linker is relatively stable while in blood circulation and becomes unstable and releases the drug molecules once it is internalized by cells $(9,10)$. 
It is important to note that dendrimers, synthetic superma cromolecules with highly branched repeated three dimensional structures, have emerged as important materials for biological application due to their unique features such as the precise control of size and shape, uncommon physical properties, controlled degradation, and the ability to place numerous functional groups on their periphery and/or core $(11,12)$. There are more than 50 different types of dendrimers (13). Among them, polyamidoamine and poly (propylenemine) have been commercialized and used extensively as biomaterials in gene and drug delivery $(14,15)$ and for nanoparticle encapsulation $(16,17)$ in imaging $(18,19)$.

\section{Liposomal nanoparticles}

Liposomes are self-assembling spherical particles with a membrane composed of phospholipid bilayers. The size of liposomes can range from $25 \mathrm{~nm}$ to $10 \mu \mathrm{m}$ depending on the preparation method. They have been studied as candidates for drug delivery for the last 50 years since being first discovered by Bangham (20). The synthesis of liposomal nanoparticles has been reviewed by Bellare, et al (21). Drug delivery systems based on unmodified liposomes are limited by their short blood circulation time. This is mainly due to the fast clearance of liposomes by macrophages of the reticuloendothelial system (RES) (22). The second generation of polymer-coated liposomes can dramatically increase blood circulation times from several minutes up to 3 days.

\section{Gold and iron oxide nanoparticles}

Recently, several novel nanotechnology concepts have been applied to the development of a new generation of anti-cancer drug delivery systems. Gold nanoparticles can be synthesized through the reduction of $\mathrm{HAlCl}_{4}$ with a very narrow polydispersity. Several gold nanoparticle anticancer drug delivery systems have been reported and showed good in vitro results (23). Although it seems that gold is inert under physiological environments, the long term toxicity of gold nanoparticles remains an unanswered question. One attractive property of gold nanoparticles is that gold concentrations are naturally low in animal bodies, allowing the convenient use of this nanoparticle model for in vivo pharmacokinetic and biodistribution studies (24).

It is worth mentioning that a gold nanorod formulation is showing very promising potential as a photothermal therapy agent. Gold nanorod can generate heat when it is radiated by a near infra-red (IR) laser (wavelengt $>650 \mathrm{~nm}$ ). At this range, the laser is relatively safe to the tissue and organs. Once the gold nanorod has accumulated inside the tumor through passive/active targeting, it can be heated locally up to $43^{\circ} \mathrm{C}$ (25) by radiation with a near IR laser to destroy the tumor without causing damage to surrounding healthy tissues (27).

Iron oxide nanoparticles have been clinically used as imaging agents for MRI. Recently a number of research groups have investigated them as drug carriers while retaining their imaging functions (26-28). One unique advantage of iron oxide nanoparticle delivery systems is that they can be delivered in a targeted manner to a desired region by applying an external magnetic field.

\section{Properties of Nanoparticles}

A suitable nanoparticle size is very important for efficient drug delivery. Generally, 10 100 nm is considered the optimal size for nanoparticle drug carriers. If the particle size is less than $10 \mathrm{~nm}$, the nanoparticles will be quickly eliminated by renal clearance (threshhold $<6 \mathrm{~nm}$ ). At sizes greater than $100 \mathrm{~nm}$, the chance of the particle being captured by the RES will dramatically increase (29).

A proper surface coating is essential to the stability and circulation time of nanoparticle delivery systems. For instance, a sodium citrate-stabilized gold particle aggregates in PBS within several minutes. But once coated with thiol-terminated polyethylene glycol (PEG) polymer, this nanoparticle is stable not only in PBS but also under low or high $\mathrm{pH}$ conditions (32). Generally, a neutralcharged nanoparticle can achieve a long circulation time and reduce the chance of nanoparticle capture by the immune system.

\section{Targeted Delivery of Therapeutic Nanoparticles}

\section{$1 \overline{\text { Passive targeting }}$}

Table 1 lists nanoparticles that have been used in the clinic and utilize passive targeting to achieve their selective delivery to tumors. Passive targeting takes advantage of the inherent size of nanoparticles and the unique properties of tumor vasculature (3033). As tumors grow and begin to outstrip the available supply of oxygen and nutrients, they release cytokines and other signaling molecules that recruit new blood vessels to the tumor in a process called angiogenesis. Unlike the tight blood vessels in normal tissues, angiogenic blood vessels in tumor tissues have gaps as large as 600 to $800 \mathrm{~nm}$ between adjacent endothelial cells $(34,35)$. This defective vascular architecture coupled with poor lymphatic drainage induces an enhanced permeability and retention effect (EPR) $(36,37)$, Through these gaps, nanoparticles can selectively accumulate into the tumor interstitium (38) (Fig. 2).

In general, the accumulation of nanoparticles in tumor tissues is dependent on several factors including the size, surface characteristics, and circulation half-life of the nanoparticles and the degree of angiogenesis of the tumor (39). It is speculated that nanoparticles with a size between 10 and $100 \mathrm{~nm}$ will be optimal for tumor accumulation. For example, smaller polymeric micelles (20 


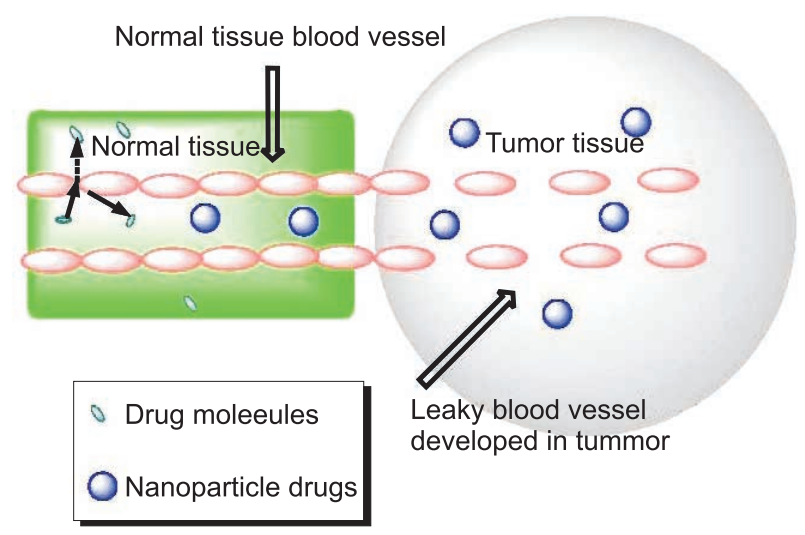

Fig. 2. Schematic diagram of nanoparticle accumulation in tumor tissue through EPR effect. Normal tissue vasculatures are lined by tight endothelial cells, thereby preventing nanoparticle drugs from escaping, whereas tumor tissue vasculatures are leaky and hyperpermeable allowing preferential accumulation of nanoparticles in the tumor interstitial space (passive targeting). $\mathrm{nm}$ ) have been shown to accumulate more readily in tumors than larger liposomes $(100 \mathrm{~nm})(40,41)$. Proper surface characteristics and longer circulation times of nanoparticles can also improve tumor uptake, as described earlier. The unmodified phospholipid surface of liposomes can attract plasma proteins and thus recognition by the mononuclear phagocytic system (MPS), resulting in their rapid clearance from the circulation. This property impedes the distribution of liposome-associated drugs to solid tumors. Surface-modified (stealth) liposomes have solved the problem of fast clearance from the circulation, yielding liposomes with a significantly increased half-life in the blood $(42,43)$. Dramatically reduced clearance rates have also been obtained with other nanoparticles such as Abraxane (44), Xyotax (45) and IT-101 (46). Tumor vascularization also affects nanoparticle accumulation; usually nanoparticles accumulate poorly in poorly vascularized tumors, small pre-angiogenic tumors, or large necrotic tumors.

As drug delivery systems, nanoparticles have shown an ability to improve pharmacokinetics, pharmacodynamics, efficacy, and to reduce the toxicity of associated drugs (40). For example, Abraxane

Table 1. Examples of non-targeted nanoparticles in clinical development

\begin{tabular}{|c|c|c|c|}
\hline Type of Nanoparticle & Name and Refs & Therapeutic agent & Status \\
\hline \multirow[t]{10}{*}{ Liposomes } & DaunoXome $^{\circledR}(105)$ & Dox & Approved \\
\hline & Doxil $^{\circledR} /$ Caelyx $^{\circledR}(39,51)$ & Dox & Approved \\
\hline & Myocet $^{\circledR}(39,106,107)$ & Dox & Approved (Europe) \\
\hline & SPI-077 (108 110) & Cisplatin & Phase II \\
\hline & Oncolipin (111) & Interleukin 2 & Phase II \\
\hline & OSI-7904L $(112,113)$ & Thymidylate synthase inhibitor & Phase II \\
\hline & LEP ETU (114) & Paclitaxel & Phase I/II \\
\hline & LE-SN38 $(18,19)$ & SN-38 & Phase I/II \\
\hline & OSI-211 (115) & lurtotecan & Phase II \\
\hline & Aroplatin (116) & Oxaliplatin & Phase II \\
\hline \multirow[t]{6}{*}{ Polymeric micelles } & Genexol-PM $(85,117 \sim 119)$ & Paclitaxel & Approved (South Korea) \\
\hline & NK911 $(52,120)$ & Dox & Phase I \\
\hline & SP1049C (121) & Dox & Phase I \\
\hline & NC-6004 (122) & Cisplatin & Phase I \\
\hline & NK012 $(122,123)$ & SN-38 & Phase I \\
\hline & NK105 $(50,124)$ & Paclitaxel & Phase I \\
\hline \multirow[t]{13}{*}{ Polymer-drug conjugate-based nanoparticles } & CT-2103; $\operatorname{Xyotax}^{\mathrm{TM}}(45,125)$ & Paclitaxel & Phase III \\
\hline & PK1; FCE28068 $(126,127)$ & Dox & Phase II \\
\hline & PK2; FCE28069 (128) & Dox & Phase I/II \\
\hline & PNU166945 (97) & Paclitaxel & Phase I \\
\hline & MAG-CPT $(129,130)$ & Camptothecin & Phase I \\
\hline & AP5280 (131) & Platinate & Phase I/II \\
\hline & AP5346 (132) & Platinum & Phase II \\
\hline & AD-70, DOX-OXD (133) & Dox & Phase I \\
\hline & DE-310 (134 136) & Camptothecin & Phase I/II \\
\hline & Prothecan $(137,138)$ & Camptothecin & Phase II \\
\hline & EZN-2208 (139) & SN-38 & Phase I \\
\hline & IT-101 (82) & Camptothecin & Phase II \\
\hline & NKTR-102 (140) & Irinotecan & Phase II \\
\hline Albumin-based nanoparticles & Abraxane $(47,141,142)$ or ABI-007 & Paclitaxel & Approved \\
\hline
\end{tabular}


(ABI-007), an albumin-bound nanoparticle of paclitaxel (Taxol) which has been approved for the treatment of metastatic breast cancer, showed significant greater efficacy than free paclitaxel in a phase III clinic trial (47). Despite the increased dose of paclitaxel in the Abraxane group, the incidence of grade 4 neutropaenia was significantly lower than in patients treated with free paclitaxel. Pharmacokinetic studies also showed that paclitaxel clearance and the volume of distribution were higher for Abraxane than for paclitaxel: Clearance was 13 litres per hour per $\mathrm{m}^{2}$ for Abraxane versus 14.76 litres per hour per $\mathrm{m}^{2}$ for paclitaxel $(\mathrm{p}=0.048)$, and distribution was 663.8 litres per $\mathrm{m}^{2}$ for Abraxane versus 433.4 litres per $\mathrm{m}^{2}$ for paclitaxel $(\mathrm{p}=0.04)$ (44). Similar to Abraxane, NK105, a micellar nanoparticle formulation of paclitaxel also showed improved pharmacokinetics, pharmacodynamics, efficacy, and reduced toxicity as compared with free paclitaxel in a preclinical study and a phase I trial $(48,49)$. The plasma area under the curve (AUC) value was approximately 90 -fold greater for NK105 than for free paclitaxel and the tumor AUC value was 25 -fold higher for NK105 than for free paclitaxel in an animal model (48). In patients, the plasma AUC of NK105 at $180 \mathrm{mg} / \mathrm{m}^{2}$ was approximately 30 fold greater than that of the conventional formulation of paclitaxel (49). NK105 showed significantly more potent antitumor activity in a human colorectal cancer cell line HT-29 xenograft than free paclitaxel, due to enhanced accumulation of the drug in the tumor (48). The phase I trial showed that NK105 was well tolerated and effective in patients with pancreatic cancer (50). These differences in pharmacokinetic properties may contribute to the increased drug accumulation inside the tumor observed with nanoparticles compared with the corresponding free drugs. Other nanoparticles currently used in the clinic or undergoing clinic trials also showed an improved pharmacokinetic profile compared with the respective free drugs, such as Doxil, a PEG-liposome loaded with doxorubicin (DOX) (51), SP1049C, a pluronic micelle loaded with DOX (40), NK911, a PEG-Asp micelle loaded with DOX (52), and Xyotax, a polyglutamic acid nanoparticle carrying paclitaxel (45).

\section{$2 \overline{\text { Active targeting }}$}

The nanoparticles listed in Table 1 that have been used in the clinic so far mostly utilize the EPR effect of tumors and the tumor microenvironment to promote their selective delivery to tumors. However, certain limitations of non-targeted nanoparticles as a drug delivery system still remain. For example, in the case of the EPR effect, although poor lymphatic drainage helps the extravasated drugs to be enriched in the tumor interstitium, it also induces drug outflow from the cells as a result of higher osmotic pressure in the interstitium, which eventually leads to drug redistribution in some portions of the cancer tissue (53). Most importantly, accumulation merely within the tumor microenvironment by the EPR effect may not always correlate with therapeutic efficacy since internalization into the tumor cells is required for most anticancer drugs to exert

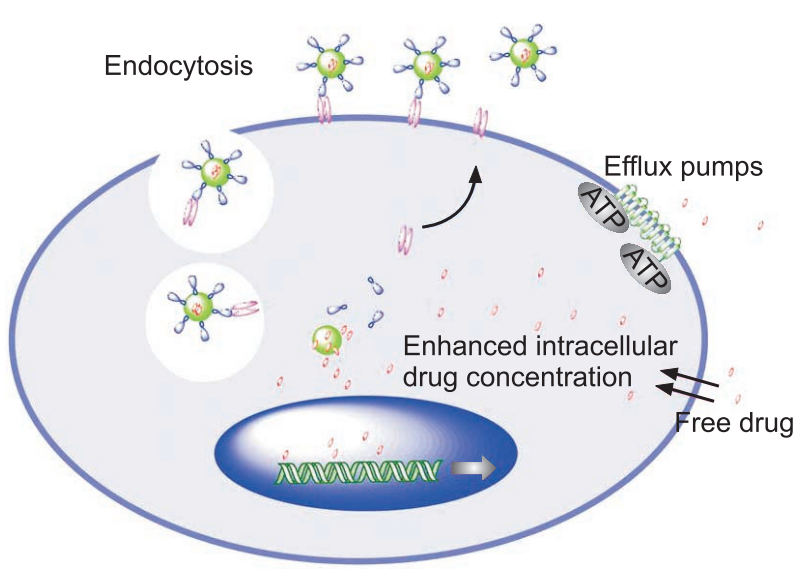

Fig. 3. Internalization of nanoparticles via receptor-mediated endocytosis. Tumor-specific ligands/antibodies on the nanoparticles bind to cell through an endosome-dependent mechanism. Drugloaded nanoparticles bypass the drug efflux pump not being recognized when the drug enters cells, leading to high intracellular concentration.

their biological functions. To overcome these limitations, a rational approach is to incorporate a targeting moiety on the nanoparticle surface. The targeting moiety is expected to bind a tumor-associated antigen or receptor and facilitate the delivery of nanoparticles to the intracellular site of drug action, enabling a greater therapeutic effect (Fig. 3). Recent preclinical studies have shown that targeted nanoparticles have better antitumor activity compared with nontargeted nanoparticles (54-57). Although targeted nanoparticles may not always mediate an increase in tumor drug accumulation when compared with non-targeted nanoparticles, targeted nanoparticles show greater intracellular drug delivery to cancer cells than nontargeted nanoparticles, resulting in dramatically increased antitumor efficacy (54-56). These findings suggest that the primary role of the targeting ligands is to enhance cellular uptake into cancer cells and to minimize cellular uptake in normal cells.

Although current studies have shown that the use of targeted nanoparticles as a drug delivery system is a promising strategy to treat human cancers, it is still in its early stage of development. Clinical data using targeted nanoparticles are limited since most targeted nanoparticles have not yet reached the clinic. Only a few targeted nanoparticles are currently under clinical investigation. One is MCC-465, which is an immunoliposome-encapsulated doxorubicin (Dox). The liposome is tagged with PEG and the $\mathrm{F}(\mathrm{ab})_{2}$ fragment of the human monoclonal antibody GAH, which recognizes a cell surface molecule on various types of cancer cells (58). Phase I studies have indicated that the PK parameters of MCC465 differ from those of free Dox, but were very similar to those of Doxil (non-targeted liposome-encapsulated Dox) in humans. In terms of skin toxicity, the patients who received MCC-465 did not experience any severe skin toxicity such as palmar-plantar erythrodysesthesia (PPE) or mucositis, unlike the patients who 
received Doxil (58). Besides MCC-465, other examples of targeted therapeutic nanoparticles include MBP-426 which contains the cytotoxic platinum-based drug oxaliplatin in a liposome (59), SGT53, a liposome containing a plasmid coding for the tumor suppressor p53 (60), and CALAA-01, a polymer-siRNA conjugate $(61,62)$ (Table 2). These nanoparticles all target the transferrin receptor which is upregulated in many types of cancer (63).

\section{Selection of target receptor and ligand}

Selection of the target receptor or antigen on cancer cells is crucial for the optimal design of targeted nanoparticles. In general, cell-surface antigens and receptors should have several properties that render them particularly suitable as tumor-specific targets. First, they should be abundantly and uniquely expressed on tumor cells, but negligibly or less expressed on normal cells. Second, they should have a high density on tumor cells.

A targeting ligand should selectively and successfully transport nanoparticles into targeted cancer cells. It is believed that internalization of nanoparticles after binding to targeted tumor cells is necessary for good therapeutic responses, so whether the targeted nanoparticles can be internalized is an important issue in the selection of proper targeting ligand. Use of a ligand that can not trigger the internalization process may result in drug release outside the cell and its redistribution to the surrounding normal tissues.

A variety of targeting ligands, including antibodies, antibody fragments, peptides, growth factors, and aptamers (64), have been used to facilitate the uptake of carriers into target cells (65-76).

\section{Reduction of Multidrug Resistance}

Drug resistance remains one of the major challenges in cancer therapy. A number of mechanisms for drug resistance have been described. Drug resistance can be caused by physiological barriers (non-cellular based mechanisms), or alterations in the biology and biochemistry of cancer cells (cellular mechanisms). Non-cellular drug resistance can be caused by poorly vascularized tumor regions and/or physiological barriers that greatly reduce drug access to the tumor tissues, thus protecting cancerous cells from drug-induced cytotoxicity. Cellular drug resistance can be due to overexpressed drug export pumps, such as P-glycoprotein (p-gp) and other drugresistance proteins, increased DNA repair capacity, and reduced apoptosis regulation.

Among these mechanisms, the roles of the drug efflux pumps are the most extensively investigated. P-glycoprotein (p-gp), a product of the MDR1 gene, is a $170-\mathrm{kD}$ transmembrane glycoprotein that functions as an efflux pump to remove drug from cells. Several specific p-gp inhibitors have been investigated to overcome drug resistance. Although in preclinical studies, some of these p-gp inhibitors have shown the restoration of cancer cell sensitivity to anticancer drugs, the clinical trials results have been disappointing $(77,78)$.

Alternative strategies for overcoming drug resistance have been studied. Newly developed drug delivery systems, including nanoparticle, allow selective drug accumulation in tumor tissues, tumor cells, or even compartments of tumor cells. Because with the aid of a targeting moiety nanoparticles enter cells through endocytosis, it is expected that they can bypass the p-gp efflux pump, leading to their greater intracellular accumulation (Fig. 3). Many nanoparticles have been used to overcome or minimize drug resistance in preclinical studies and the results are very promising. For example, doxorubicin (DOX)-loaded poly (alkyl cyanoacrylate) nanoparticles (79), PACA nanoparticle $(80,81)$, and IT-101 (a

Table 2. Examples of targeted nanoparticles in preclinical and clinical development

\begin{tabular}{llll}
\hline Name and Refs & Targeting agent & Therapeutic agent & Status \\
\hline FCE28069 (128) & Galactose & DOX & Phase I (stopped) \\
MCC-465 (58) & F(ab')2 fragment of & DOX & Phase I \\
& human antibody GAH & Phase I \\
MBP-426 (59) & Transferrin & Oxaliplatin & Phase I \\
SGT-53 (60) & Transferrin receptor antibody fragment & Plasmid DNA with p53 gene \\
CALAA-01 (62) & Transferrin & Small interfering RNA & Phase I \\
DOX-PEG-FOL (143) & Folate receptor & Dox & Pre-clinic \\
cRGD-Functionalized Dox micelle (144) & cRGD peptide & Dox & Pre-clinic \\
Dtxl-NP-Apt (56) & RNA aptamer & Dox & Pre-clinic \\
2C5 -Immunomicelles (145) & mAntibody 2C5 & Paclitaxel & Pre-clinic \\
ASGPR-paclitaxel (146) & Galactosel & Paclitaxe & Pre-clinic \\
Pt-NP-Apt (64) & PSMA targeting aptamer & Cisplatin & Pre-clinic \\
\hline
\end{tabular}


nanoparticulate conjugate of 20 (S)-camptothecin) (82) have shown the ability to overcome drug resistance in the tested models. And most importantly, the ability of targeted nanoparticles to overcome drug resistance has been confirmed in humans. It has been demonstrated in clinical studies that liposomal doxorubicin is able to overcome drug resistance in AIDS-related Kaposi's sarcoma $(83,84)$. Also, clinical trials showed positive results using nanoparticles in patients who had previously failed chemotherapy $(83,85,86)$. Ligand-targeted strategies, especially those using receptor-targeting ligands, have also been applied to overcome drug resistance since these ligands are internalized via receptor-mediated endocytosis, bypassing the plasma membrane where $\mathrm{p}$-gp primarily acts. As an example, folate receptor-targeted $\mathrm{pH}$-sensitive polymeric micelles containing DOX (87) and transferrin-conjugated paclitaxel nanoparticles exhibited greater cytotoxicity than the respective free drugs in a drug-resistant model (88). As illustrated, using nanoparticles as a drug delivery system may be able to overcome certain kinds of cancer drug resistance.

\section{Potential Toxicity of Nanoparticles}

An important consideration in nanoparticle development is the biological behavior of carrier constituents and their potential toxicity, especially during chronic administration. Many candidate polymers have been defined with particular toxicities, such as hematotoxicity, complementactivation, carcinogenicity, teratogenicity, and immunogenicity $(89,90)$, indicating the importance of choosing safe polymers for the design of nanoparticles. In addition, the biological properties of polymers are molecular weight-dependent and can be changed once the respective conjugates are prepared. Therefore, careful characterization of the potential toxicity of both the polymer and the final nanoparticle is critically important. For nonbiodegradable polymers, potential toxicity is concerning when the polymer molecular weight is greater than the renal threshold. Increased understanding of the potentially deleterious properties of polymers leads to the design of new and safer polymeric nanoparticles.

Currently, most nanoparticles use nontoxic and biodegradable ingredients, so toxicities associated with the carrier molecules per se tend to be mild. However, particular nanoparticles cause increased accumulation of drugs in MPS cells in the liver, spleen, and bone marrow, with the possibility of increased toxicities to these organs. Among these organs, the liver has been identified in many studies as the primary organ responsible for reticuloendothelial capture of nanoparticles, often due to phagocytosis by Kupffer cells $(91,92)$. Hepatic uptake has been shown to be a main mechanism of hepatic clearance from the blood circulation following the intravenous injection of nanoparticles. In addition to hepatic accumulation, some nanoparticles have been reported to cause liver injury (decreased function and hepatic morphology changes) $(93,94)$. For example, intravenous administration of cationic PAMAM dendrimers caused liver injury when administered intravenously to mice (95). Hepatotoxicity has also been observed in mice treated orally with nano-zinc particles (96). Also there are safety concerns with particular nanoparticles that are able to cross the blood brain barrier. Lessons have been learned from many of the early clinical studies. For example, due to neurotoxicity, a clinical trial testing an HPMAconjugated paclitaxel was terminated (97). The failure of MAGcamptothecin due to cumulative bladder toxicity in phase I was also reported (98).

Attempts are being made to decrease the uptake of nanoparticles by MPS cells and to increase their accumulation in the active site, through polymer or nanoparticle surface modifications, and/or incorporating targeting ligands $(54,99,100)$. With more rational design, many nanoparticles have shown an improved safety profile and enhanced antitumor efficacy compared with free drugs in preclinical and clinical studies (100-104). For example, Doxil (PEGliposome loaded with doxorubicin) showed a reduction in cardiotoxicity over that of doxorubicin in a clinical study $(103,104)$. Abraxane (albumin nanoparticle loaded with paclitaxel) showed a greater therapeutic outcome compared with free paclitaxel and, taking advantage of the water solubility of the nanoparticle, successfully eliminated the side effects associated with the toxic vehicle Cremophor EL (47).

\section{Implications and Future Directions}

Nanoparticles provide opportunities for designing and tuning properties that are not possible with other types of therapeutic drugs, and have shown a bright future as a new generation of cancer therapeutics. Furthermore, the development of multifunctional nanoparticles may eventually render nanoparticles able to detect and kill cancer cells simultaneously. Although there are certain critical questions and many challenges remaining for the clinical development of nanoparticles, as more clinical data are available, further understanding in nanotechnology will certainly lead to the more rational design of optimized nanoparticles with improved selectivity, efficacy, and safety.

\section{Acknowledgement}

We thank Dr. Anthea Hammond for her critical reading of the manuscript. 


\section{References}

1. Qiu LY, Bae YH. Polymer architecture and drug delivery. Pharm Res. 2006;23:1-30.

2. Tong R, Cheng JJ. Anticancer polymeric nanomedicines. Polym Rev. 2007;47:345-81.

3. Cho K, Wang X, Nie S, Chen ZG, Shin DM. Therapeutic nanoparticles for drug delivery in cancer. Clin Cancer Res. 2008;14:1310-6.

4. Zhang GZ, Niu AZ, Peng SF, Jiang M, Tu YF, Li M, et al. Formation of novel polymeric nanoparticles. Acconuts Chem Res. 2001;34:249-56.

5. Park K, Kim K, Kwon IC, Kim SK, Lee S, Lee DY, et al. Preparation and characterization of self-assembled nanoparticles of heparin-deoxycholic acid conjugates. Langmuir. 2004;20:11726-31.

6. Park K, Lee GY, Kim YS, Yu M, Park RW, Kim IS, et al. Heparin-deoxycholic acid chemical conjugate as an anticancer drug carrier and its antitumor activity. J Control Release. 2006;114:300-6.

7. Kratz F, Beyer U, Schutte MT. Drug-polymer conjugates containing acid-cleavable bonds. Crit Rev Ther Drug. 1999;16:245-88.

8. Ulbrich K, Subr V. Polymeric anticancer drugs with pH-controlled activation. Adv Drug Deliver Rev. 2004;561023-50.

9. Jones DP, Carlson JL, Samiec PS, Sternberg P, Mody VC, Reed RL, et al. Glutathione measurement in human plasma Evaluation of sample collection, storage and derivatization conditions for analysis of dansyl derivatives by HPLC. Clin Chim Acta. 1998;275:175-84.

10. Koo AN, Lee HJ, Kim SE, Chang JH, Park C, Kim C, et al. Disulfide-cross-linked PEGpoly(amino acid)s copolymer micelles for glutathione-mediated intracellular drug delivery. Chem Comm. 2008:6570-2.

11. Bosman AW, Janssen HM, Meijer EW. About dendrimers: Structure, physical properties, and applications. Chem Rev. 1999;99:1665-88.

12. Fischer M, Vogtle F. Dendrimers: From design to application - A progress report. Angew Chem Int Edit. 1999;38:885-905.

13. Klajnert B, Bryszewska M. Dendrimers: properties and applications. Acta Biochimica Polonica. 2001;48:199-208.

14. Dykes GM. Dendrimers: a review of their appeal and applications. J Chem Tech Biot. 2001;76:903-18.

15. Esfand R, Tomalia DA. Poly(amidoamine) (PAMAM) dendrimers: from biomimicry to drug delivery and biomedical applications. Drug Discov Today. 2001;6:427-36.

16. Balogh L, Tomalia DA. Polylamidoamine) dendrimer-templated nanocomposites. 1. Synthesis of zerovalent copper nanoclusters. J Am Chem Soc. 1998;120:7355-6.

17. Crooks RM, Zhao MQ, Sun L, Chechik V, Yeung LK. Dendrimer-encapsulated metal nanoparticles: Synthesis, characterization, and applications to catalysis. Acconuts Chem Res. 2001;34:181-90.

18. Balogh L, Bielinska A, Eichman JD, Valluzzi R, Lee I, Baker JR, et al. Dendrimer nanocomposites in medicine. Chim Oggi. 2002;20:35-40.

19. Zheng J, Dickson RM. Individual water-soluble dendrimer-encapsulated silver nanodot fluorescence. J Am Chem Soc. 2002;124:13982-3.

20. Bangham AD, Horne RW. Negative Staining of Phospholipids + Their Structural Modification by-Surface Active Agents as Observed in Electron Microscope. J Mol Biol. 1964;8:660-8.

21. Watwe RM, Bellare JR. Manufacture of Liposomes - a Review. Curr Sci. 1995;68: 71524.

22. Gabizon AA. Stealth liposomes and tumor targeting: One step further in the quest for the magic bullet. Clin Cancer Res. 2001;7:223-5.

23. Cheng Y, Samia AC, Meyers JD, Panagopoulos I, Fei BW, Burda C. Highly efficient drug delivery with gold nanoparticle vectors for in vivo photodynamic therapy of cancer. J Am Chem Soc. 2008;130:10643-7.

24. Oian X, Peng XH, Ansari DO, Yin-Goen D, Chen GZ, Shin DM, et al. In vivo tumor targeting and spectroscopic detection with surface-enhanced Raman nanoparticle tags. Nat Biotechnol. 2008;26:83-90.

25. Dewey WC. Arrhenius Relationships from the Molecule and Cell to the Clinic. Int J Hyperther. 1994;10:457-83
26. Sun C, Lee JSH, Zhang MQ. Magnetic nanoparticles in MR imaging and drug delivery. Adv Drug Deliver Rev. 2008;60:1252-65.

27. Jun YW, Lee JH, Cheon J. Chemical design of nanoparticle probes for highperformance magnetic resonance imaging. Angew Chem Int Edit. 2008;47:5122-35.

28. Xu CJ, Sun SH. Monodisperse magnetic nanoparticles for biomedical applications. Polym Int. 2007;56:821-6.

29. Davis ME, Chen ZG, Shin DM. Nanoparticle therapeutics: an emerging treatment modality for cancer. Nat Rev Drug Discov. 2008;7:771-82.

30. Gao X, Cui Y, Levenson RM, Chung LW, Nie S. In vivo cancer targeting and imaging with semiconductor quantum dots. Nat Biotechnol. 2004;22:969-76.

31. Jain TK, Morales MA, Sahoo SK, Leslie-Pelecky DL, Labhasetwar V. Iron oxide nanoparticles for sustained delivery of anticancer agents. Mol Pharm. 2005;2:194-205.

32. Pelicano H, Martin DS, Xu RH, Huang P. Glycolysis inhibition for anticancer treatment. Oncogene. 2006;25:4633-46.

33. Deryugina El, Quigley JP. Matrix metalloproteinases and tumor metastasis. Cancer Metastasis Rev. 2006;25:9-34.

34. Edens HA, Levi BP, Jaye DL, Walsh S, Reaves TA, Turner JR, et al. Neutrophil transepithelial migration: evidence for sequential, contact-dependent signaling events and enhanced paracellular permeability independent of transjunctional migration. J Immunol. 2002;169:476-86.

35. Wang X, Yang L, Chen ZG, Shin DM. Application of nanotechnology in cancer therapy and imaging. CA Cancer J Clin. 2008;58:97-110.

36. Jain RK. Transport of molecules across tumor vasculature. Cancer Metastasis Rev. 1987;6:559-93.

37. Brannon-Peppas L, Blanchette J0. Nanoparticle and targeted systems for cancer therapy. Adv Drug Deliv Rev. 2004;56:1649-59.

38. Cuenca AG, Jiang H, Hochwald SN, Delano M, Cance WG, Grobmyer SR. Emerging implications of nanotechnology on cancer diagnostics and therapeutics. Cancer. 2006;107:459-66.

39. Allen TM, Cullis PR. Drug delivery systems: entering the mainstream. Science. 2004;303:1818-22.

40. Sutton D, Nasongkla N, Blanco E, Gao J. Functionalized micellar systems for cancer targeted drug delivery. Pharm Res. 2007;24:1029-46.

41. Weissig V, Whiteman KR, Torchilin VP. Accumulation of protein-loaded longcirculating micelles and liposomes in subcutaneous Lewis lung carcinoma in mice. Pharm Res. 1998;15:1552-6.

42. Papahadjopoulos D, Gabizon A. Liposomes designed to avoid the reticuloendothelial system. Prog Clin Biol Res. 1990;343:85-93.

43. Wagner V, Dullaart A, Bock AK, Zweck A. The emerging nanomedicine landscape. Nat Biotechnol. 2006;24:1211-7.

44. Sparreboom A, Scripture CD, Trieu V, Williams PJ, De T, Yang A, et al. Comparative preclinical and clinical pharmacokinetics of a cremophor-free, nanoparticle albuminbound paclitaxel (ABI-007) and paclitaxel formulated in Cremophor (Taxol). Clin Cancer Res. 2005;11:4136-43.

45. Boddy AV, Plummer ER, Todd R, Sludden J, Griffin M, Robson L, et al. A phase I and pharmacokinetic study of paclitaxel poliglumex (XYOTAX), investigating both 3-weekly and 2-weekly schedules. Clin Cancer Res. 2005;11:7834-40.

46. Schluep T, Cheng J, Khin KT, Davis ME. Pharmacokinetics and biodistribution of the camptothecin-polymer conjugate IT-101 in rats and tumor-bearing mice. Cancer Chemother Pharmacol. 2006;57:654-62.

47. Gradishar WJ, Tjulandin S, Davidson N, Shaw H, Desai N, Bhar P, et al. Phase III trial of nanoparticle albumin-bound paclitaxel compared with polyethylated castor oilbased paclitaxel in women with breast cancer. J Clin Oncol. 2005;23:7794-803.

48. Hamaguchi T, Matsumura Y, Suzuki M, Shimizu K, Goda R, Nakamura I, et al. NK105, a paclitaxel-incorporating micellar nanoparticle formulation, can extend in vivo antitumour activity and reduce the neurotoxicity of paclitaxel. $\mathrm{Br} \mathrm{J}$ Cancer. 2005:92:1240-6. 
49. Kato K, Hamaguchi T, Yasui H, Okusaka T, Ueno H, lkeda M, et al. Phase I study of NK105, a paclitaxel-incorporating micellar nanoparticle in patients with advanced cancer. Proc Am Soc Clin Oncol. 2006;24:83S (abstract 2018).

50. Hamaguchi T, Kato K, Yasui H, Morizane C, Ikeda M, Ueno H, et al. A phase I and pharmacokinetic study of NK105, a paclitaxel-incorporating micellar nanoparticle formulation. Br J Cancer. 2007;97:170-6.

51. Charrois GJ, Allen TM. Drug release rate influences the pharmacokinetics, biodistribution, therapeutic activity, and toxicity of pegylated liposomal doxorubicin formulations in murine breast cancer. Biochim Biophys Acta. 2004;1663:167-77.

52. Matsumura Y, Hamaguchi T, Ura T, Muro K, Yamada Y, Shimada Y, et al. Phase I clinical trial and pharmacokinetic evaluation of NK911, a micelle-encapsulated doxorubicin. Br J Cancer. 2004;91:1775-81.

53. Stohrer M, Boucher Y, Stangassinger M, Jain RK. Oncotic pressure in solid tumors is elevated. Cancer Res. 2000;60:4251-5.

54. Kirpotin DB, Drummond DC, Shao Y, Shalaby MR, Hong K, Nielsen UB, et al. Antibody targeting of long-circulating lipidic nanoparticles does not increase tumor localization but does increase internalization in animal models. Cancer Res. 2006;66:6732-40.

55. Bartlett DW, Su H, Hildebrandt IJ, Weber WA, Davis ME. Impact of tumor-specific targeting on the biodistribution and efficacy of siRNA nanoparticles measured by multimodality in vivo imaging. Proc Natl Acad Sci U S A. 2007;104:15549-54.

56. Farokhzad OC, Cheng J, Teply BA, Sherifi I, Jon S, Kantoff PW, et al. Targeted nanoparticle-aptamer bioconjugates for cancer chemotherapy in vivo. Proc Natl Acad Sci U S A. 2006;103:6315-20.

57. Gu F, Zhang L, Teply BA, Mann N, Wang A, Radovic-Moreno AF, et al. Precise engineering of targeted nanoparticles by using self-assembled biointegrated block copolymers. Proc Natl Acad Sci U S A. 2008;105:2586-91.

58. Matsumura Y, Gotoh M, Muro K, Yamada Y, Shirao K, Shimada Y, et al. Phase I and pharmacokinetic study of MCC-465, a doxorubicin (DXR) encapsulated in PEG immunoliposome, in patients with metastatic stomach cancer. Ann Oncol. 2004;15:517-25.

59. MedBiopharm Co. L. Safety study of MBP-426 (liposomal oxaliplatin suspension for injection) to treat advanced or metastatic solid tumors. ClinivalTrials.gov web site 2008 [online], http;//www.clinicaltrials.gove/ct/show/NCT00355888/

60. SynerGene Therapeutics I. safety study of infusion of SGT-53 tp treat solid tumors. ClinicalTrials.gov web site 2008 [online], http://www.clincaltrials.gov/ct2/show/NCT00470613/

61. Heidel JD, Yu Z, Liu JY, Rele SM, Liang Y, Zeidan RK, et al. Administration in nonhuman primates of escalating intravenous doses of targeted nanoparticles containing ribonucleotide reductase subunit M2 siRNA. Proc Natl Acad Sci U S A. 2007;104: 5715-21.

62 Calando-Pharmaceuticals. Safety study of CALAA-01 to treat solid tumor cancers. ClinicalTrials.gov web site 2008 [online], http://www.clincaltrials.gov/ct/show/NCT00689065

63. Gatter KC, Brown G, Trowbridge IS, Woolston RE, Mason DY. Transferrin receptors in human tissues: their distribution and possible clinical relevance. J Clin Pathol. 1983:36:539-45.

64. Dhar S, Gu FX, Langer R, Farokhzad OC, Lippard SJ. Targeted delivery of cisplatin to prostate cancer cells by aptamer functionalized Pt(IV) prodrug-PLGA-PEG nanoparticles. Proc Natl Acad Sci U S A. 2008;105: 17356-61.

65. Mansour AM, Drevs J, Esser N, Hamada FM, Badary OA, Unger C, et al. A new approach for the treatment of malignant melanoma: enhanced antitumor efficacy of an albumin-binding doxorubicin prodrug that is cleaved by matrix metalloproteinase 2 . Cancer Res. 2003;63:4062-6.

66. Kong G, Anyarambhatla G, Petros WP, Braun RD, Colvin OM, Needham D, et al. Efficacy of liposomes and hyperthermia in a human tumor xenograft model: importance of triggered drug release. Cancer Res. 2000;60:6950-7.

67. Guillemard V, Uri Saragovi H. Prodrug chemotherapeutics bypass p-glycoprotein resistance and kill tumors in vivo with high efficacy and target-dependent selectivity. Oncogene. 2004;23:3613-21.

68. Guillemard V, Saragovi HU. Novel approaches for targeted cancer therapy. Curr Cancer Drug Targets. 2004;4:313-26.

69. Pechar M, Ulbrich K, Subr V, Seymour LW, Schacht EH. Poly(ethylene glycol) multiblock copolymer as a carrier of anti-cancer drug doxorubicin. Bioconjug Chem. 2000;11:131-9.

70. Lu ZR, Gao SQ, Kopeckova P, Kopecek J. Modification of cyclosporin A and conjugation of its derivative to HPMA copolymers. Bioconjug Chem. 2001;12:129-33.

71. Li C. Poly(L-glutamic acid)--anticancer drug conjugates. Adv Drug Deliv Rev. 2002;54: 695-713.

72. Sudimack J, Lee RJ. Targeted drug delivery via the folate receptor. Adv Drug Deliv Rev. 2000;41:147-62.

73. Ni S, Stephenson SM, Lee RJ. Folate receptor targeted delivery of liposomal daunorubicin into tumor cells. Anticancer Res. 2002;22:2131-5.

74. Backer MV, Gaynutdinov TI, Aloise R, Przekop K, Backer JM. Engineering S-protein fragments of bovine ribonuclease A for targeted drug delivery. Protein Expr Purif. 2002;26:455-61.

75. Backer MV, Aloise R, Przekop K, Stoletov K, Backer JM. Molecular vehicles for targeted drug delivery. Bioconjug Chem. 2002;13:462-7.

76. Saba NF, Wang X. Müller, S, Tighiouart M, Cho K, Nie S, Chen Z(G), Shin DM. Examining expression of folate receptor in squamous cell carcinoma of the head and neck as a target for a novel nanotherapeutic drug. Head and Neck. 2008;in press.

77. Ferry DR, Traunecker H, Kerr DJ. Clinical trials of P-glycoprotein reversal in solid tumours. Eur J Cancer. 1996;32A:1070-81.

78. McDevitt CA, Callaghan R. How can we best use structural information on Pglycoprotein to design inhibitors? Pharmacol Ther. 2007;113:429-41.

79. Pepin X, Attali L, Domrault C, Gallet S, Metreau JM, Reault Y, et al. On the use of ionpair chromatography to elucidate doxorubicin release mechanism from polyalkylcyanoacrylate nanoparticles at the cellular level. J Chromatogr B Biomed Sci Appl. 1997;702:181-91.

80. Vauthier C, Dubernet C, Chauvierre C, Brigger I, Couvreur P. Drug delivery to resistant tumors: the potential of poly(alkyl cyanoacrylate) nanoparticles. J Control Release. 2003:93:151-60.

81. Peracchia MT, Fattal E, Desmaele D, Besnard M, Noel JP, Gomis JM, et al. Stealth PEGylated polycyanoacrylate nanoparticles for intravenous administration and splenic targeting. J Control Release. 1999;60:121-8.

82. Schluep T, Hwang J, Cheng J, Heidel JD, Bartlett DW, Hollister B, et al. Preclinical efficacy of the camptothecin-polymer conjugate IT-101 in multiple cancer models. Clin Cancer Res. 2006;12:1606-14.

83. Northfelt DW, Dezube BJ, Thommes JA, Levine R, Von Roenn JH, Dosik GM, et al. Efficacy of pegylated-liposomal doxorubicin in the treatment of AIDS-related Kaposi's sarcoma after failure of standard chemotherapy. J Clin Oncol. 1997;15:653-9.

84. Mamot C, Drummond DC, Hong K, Kirpotin DB, Park JW. Liposome-based approaches to overcome anticancer drug resistance. Drug Resist Updat. 2003;6:271-9.

85. Lee KS, Chung HC, Im SA, Park YH, Kim CS, Kim SB, et al. Multicenter phase II trial of Genexol-PM, a Cremophor-free, polymeric micelle formulation of paclitaxel, in patients with metastatic breast cancer. Breast Cancer Res Treat. 2008;108:241-50.

86. Nemunaitis J, Cunningham C, Senzer N, Gray M, Oldham F, Pippen J, et al. Phase I study of CT-2103, a polymer-conjugated paclitaxel, and carboplatin in patients with advanced solid tumors. Cancer Invest. 2005;23:671-6.

87. Lee ES, Na K, Bae YH. Doxorubicin loaded pH-sensitive polymeric micelles for reversal of resistant MCF-7 tumor. J Control Release. 2005;103:405-18.

88. Sahoo SK, Labhasetwar V. Enhanced antiproliferative activity of transferrinconjugated paclitaxel-loaded nanoparticles is mediated via sustained intracellular drug retention. Mol Pharm. 2005;2:373-83.

89. Rihova B, Riha I. Immunological problems of polymer-bound drugs. Crit Rev Ther Drug Carrier Syst. 1985;1:311-74.

90. Duncan R. The dawning era of polymer therapeutics. Nat Rev Drug Discov. 2003;2: $347-60$.

91. Cagle DW, Kennel SJ, Mirzadeh S, Alford JM, Wilson LJ. In vivo studies of fullerenebased materials using endohedral metallofullerene radiotracers. Proc Natl Acad Sci U S A. 1999;96:5182-7.

92. Ogawara K, Furumoto K, Takakura Y, Hashida M, Higaki K, Kimura T. Surface hydrophobicity of particles is not necessarily the most important determinant in their 
in vivo disposition after intravenous administration in rats. $\mathrm{J}$ Control Release. 2001;77: 191-8.

93. Fernandez-Urrusuno R, Fattal E, Porquet D, Feger J, Couvreur P. Evaluation of liver toxicological effects induced by polyalkylcyanoacrylate nanoparticles. Toxicol Appl Pharmacol. 1995;130:272-9.

94. Roberts JC, Bhalgat MK, Zera RT. Preliminary biological evaluation of polyamidoamine (PAMAM) Starburst dendrimers. J Biomed Mater Res. 1996;30:53-65.

95. Neerman MF, Zhang W, Parrish AR, Simanek EE. In vitro and in vivo evaluation of a melamine dendrimer as a vehicle for drug delivery. Int J Pharm. 2004;281: 29-32.

96. Wang B, Feng WY, Wang TC, Jia G, Wang M, Shi JW, et al. Acute toxicity of nanoand micro-scale zinc powder in healthy adult mice. Toxicol Lett. 2006;161:115-23.

97. Meerum Terwogt JM, ten Bokkel Huinink WW, Schellens JH, Schot M, Mandjes IA, Zurlo MG, et al. Phase I clinical and pharmacokinetic study of PNU166945, a novel water-soluble polymer-conjugated prodrug of paclitaxel. Anticancer Drugs. 2001;12: 315-23.

98. Wachters FM, Groen HJ, Maring JG, Gietema JA, Porro M, Dumez H, et al. A phase I study with MAG-camptothecin intravenously administered weekly for 3 weeks in a 4-week cycle in adult patients with solid tumours. Br J Cancer. 2004;90:2261-7.

99. Clift MJ, Rothen-Rutishauser B, Brown DM, Duffin R, Donaldson K, Proudfoot L, et al. The impact of different nanoparticle surface chemistry and size on uptake and toxicity in a murine macrophage cell line. Toxicol Appl Pharmacol. 2008;232:418-27.

100. Kukowska-Latallo JF, Candido KA, Cao Z, Nigavekar SS, Majoros IJ, Thomas TP, et al. Nanoparticle targeting of anticancer drug improves therapeutic response in animal model of human epithelial cancer. Cancer Res. 2005;65:5317-24.

101. Benny 0, Fainaru 0, Adini A, Cassiola F, Bazinet L, Adini I, et al. An orally delivered small-molecule formulation with antiangiogenic and anticancer activity. Nat Biotechnol. 2008;26:799-807.

102. Langer CJ. CT-2103: emerging utility and therapy for solid tumours. Expert Opin Investig Drugs. 2004;13:1501-8.

103. Rahman AM, Yusuf SW, Ewer MS. Anthracycline-induced cardiotoxicity and the cardiac-sparing effect of liposomal formulation. Int J Nanomedicine. 2007;2:567-83.

104. Batist G. Cardiac safety of liposomal anthracyclines. Cardiovasc Toxicol. 2007;7:72-4.

105. Fassas A, Anagnostopoulos A. The use of liposomal daunorubicin (DaunoXome) in acute myeloid leukemia. Leuk Lymphoma. 2005;46:795-802.

106. Allison SD. Liposomal drug delivery. J Infus Nurs. 2007;30:89-95.

107. Sapra P, Tyagi P, Allen TM. Ligand-targeted liposomes for cancer treatment. Curr Drug Deliv. 2005;2:369-81.

108. White SC, Lorigan P, Margison GP, Margison JM, Martin F, Thatcher N, et al. Phase II study of SPI-77 (sterically stabilised liposomal cisplatin) in advanced non-small-cell lung cancer. Br J Cancer. 2006;95:822-8.

109. Rosenthal DI, Yom SS, Liu L, Machtay M, Algazy K, Weber RS, et al. A phase I study of SPI-077 (Stealth liposomal cisplatin) concurrent with radiation therapy for locally advanced head and neck cancer. Invest New Drugs. 2002;20:343-9.

110. Harrington KJ, Lewanski CR, Northcote AD, Whittaker J, Wellbank H, Vile RG, et al. Phase I-II study of pegylated liposomal cisplatin (SPI-077) in patients with inoperable head and neck cancer. Ann Oncol. 2001;12:493-6.

111. Neville ME, Boni LT, Pflug LE, Popescu MC, Robb RJ. Biopharmaceutics of liposomal interleukin 2, oncolipin. Cytokine. 2000;12:1691-701.

112. Ciuleanu T, Diculescu M, Hoepffner NM, Trojan J, Sailer V, Zalupski M, et al. A randomised phase II study of OSI-7904L versus 5-fluorouracil (FU)/leucovorin (LV) as first-line treatment in patients with advanced biliary cancers. Invest New Drugs. 2007:25:385-90

113. Clamp AR, Schoffski P, Valle JW, Wilson RH, Marreaud S, Govaerts AS, et al. A phase I and pharmacokinetic study of OSI-7904L, a liposomal thymidylate synthase inhibitor in combination with oxaliplatin in patients with advanced colorectal cancer. Cancer Chemother Pharmacol. 2008;61:579-85.

114. Guo W, Johnson JL, Khan S, Ahmad A, Ahmad I. Paclitaxel quantification in mouse plasma and tissues containing liposome-entrapped paclitaxel by liquid chromatography-tandem mass spectrometry: application to a pharmacokinetics study. Anal Biochem. 2005:336:213-20.
115. Seiden MV, Muggia F, Astrow A, Matulonis U, Campos S, Roche M, et al. A phase II study of liposomal lurtotecan (OSI-211) in patients with topotecan resistant ovarian cancer. Gynecol Oncol. 2004;93:229-32.

116. Dragovich T, Mendelson D, Kurtin S, Richardson K, Von Hoff D, Hoos A. A Phase 2 trial of the liposomal DACH platinum L-NDDP in patients with therapy-refractory advanced colorectal cancer. Cancer Chemother Pharmacol. 2006;58:759-64.

117. Kim DW, Kim SY, Kim HK, Kim SW, Shin SW, Kim JS, et al. Multicenter phase II trial of Genexol-PM, a novel Cremophor-free, polymeric micelle formulation of paclitaxel, with cisplatin in patients with advanced non-small-cell lung cancer. Ann Oncol. 2007;18:2009-14.

118. Kim SI, Shin D, Choi TH, Lee JC, Cheon GJ, Kim KY, et al. Systemic and Specific Delivery of Small Interfering RNAs to the Liver Mediated by Apolipoprotein A-I. Mol Ther. 2007;1145-52.

119. Kim TY, Kim DW, Chung JY, Shin SG, Kim SC, Heo DS, et al. Phase I and pharmacokinetic study of Genexol-PM, a cremophor-free, polymeric micelleformulated paclitaxel, in patients with advanced malignancies. Clin Cancer Res. 2004;10:3708-16.

120. Matsumura Y. [Micelle carrier system in clinical trial]. Nippon Rinsho. 2006;64:31621.

121. Danson S, Ferry D, Alakhov V, Margison J, Kerr D, Jowle D, et al. Phase I dose escalation and pharmacokinetic study of pluronic polymer-bound doxorubicin (SP1049C) in patients with advanced cancer. Br J Cancer. 2004;90:2085-91.

122. Uchino H, Matsumura Y, Negishi T, Koizumi F, Hayashi T, Honda T, et al. Cisplatinincorporating polymeric micelles (NC-6004) can reduce nephrotoxicity and neurotoxicity of cisplatin in rats. Br J Cancer. 2005;93:678-87.

123. Koizumi F, Kitagawa M, Negishi T, Onda T, Matsumoto S, Hamaguchi T, et al. Novel SN-38-incorporating polymeric micelles, NK012, eradicate vascular endothelial growth factor-secreting bulky tumors. Cancer Res. 2006;66:10048-56.

124. Negishi T, Koizumi F, Uchino H, Kuroda J, Kawaguchi T, Naito S, et al. NK105, a paclitaxel-incorporating micellar nanoparticle, is a more potent radiosensitising agent compared to free paclitaxel. Br J Cancer. 2006;95:601-6.

125. Albain KS, Belani CP, Bonomi P, O'Byrne KJ, Schiller JH, Socinski M. PIONEER: a phase III randomized trial of paclitaxel poliglumex versus paclitaxel in chemotherapynaive women with advanced-stage non-small-cell lung cancer and performance status of 2. Clin Lung Cancer. 2006;7:417-9.

126. Bilim V. Technology evaluation: PK1, Pfizer/Cancer Research UK. Curr Opin Mol Ther. 2003;5:326-30.

127. Thomson AH, Vasey PA, Murray LS, Cassidy J, Fraier D, Frigerio E, et al. Population pharmacokinetics in phase I drug development: a phase I study of PK1 in patients with solid tumours. Br J Cancer. 1999;81:99-107.

128. Seymour LW, Ferry DR, Anderson D, Hesslewood S, Julyan PJ, Poyner R, et al. Hepatic drug targeting: phase I evaluation of polymer-bound doxorubicin. J Clin Oncol. 2002:20:1668-76.

129. Bissett D, Cassidy J, de Bono JS, Muirhead F, Main M, Robson L, et al. Phase I and pharmacokinetic (PK) study of MAG-CPT (PNU 166148): a polymeric derivative of camptothecin (CPT). Br J Cancer. 2004;91:50-5.

130. Sarapa N, Britto MR, Speed W, Jannuzzo M, Breda M, James CA, et al. Assessment of normal and tumor tissue uptake of MAG-CPT, a polymer-bound prodrug of camptothecin, in patients undergoing elective surgery for colorectal carcinoma. Cancer Chemother Pharmacol. 2003;52:424-30.

131. Rademaker-Lakhai JM, Terret C, Howell SB, Baud CM, De Boer RF, Pluim D, et al. A Phase I and pharmacological study of the platinum polymer AP5280 given as an intravenous infusion once every 3 weeks in patients with solid tumors. Clin Cancer Res. 2004;10:3386-95.

132. Campone M, Rademaker-Lakhai JM, Bennouna J, Howell SB, Nowotnik DP, Beijnen $\mathrm{JH}$, et al. Phase I and pharmacokinetic trial of AP5346, a DACH-platinum-polymer conjugate, administered weekly for three out of every 4 weeks to advanced solid tumor patients. Cancer Chemother Pharmacol. 2007;60:523-33.

133. Danhauser-Riedl S, Hausmann E, Schick HD, Bender R, Dietzfelbinger H, Rastetter J, et al. Phase I clinical and pharmacokinetic trial of dextran conjugated doxorubicin 
(AD-70, DOX-OXD). Invest New Drugs. 1993;11:187-95.

134. Shiose Y, Kuga H, Yamashita F, Hashida M. Quantitative acid hydrolysis of DE-310, a macromolecular carrier system for the camptothecin analog DX-8951f. J Pharm Biomed Anal. 2007:43:1290-6.

135. Soepenberg 0, de Jonge MJ, Sparreboom A, de Bruin P, Eskens FA, de Heus G, et al. Phase I and pharmacokinetic study of DE-310 in patients with advanced solid tumors. Clin Cancer Res. 2005;11:703-11.

136. Ochi Y, Shiose Y, Kuga H, Kumazawa E. A possible mechanism for the long-lasting antitumor effect of the macromolecular conjugate DE-310: mediation by cellular uptake and drug release of its active camptothecin analog DX-8951. Cancer Chemother Pharmacol. 2005;55:323-32.

137. Greenwald RB, Choe YH, McGuire J, Conover CD. Effective drug delivery by PEGylated drug conjugates. Adv Drug Deliv Rev. 2003;55:217-50.

138. Rowinsky EK, Rizzo J, Ochoa L, Takimoto CH, Forouzesh B, Schwartz G, et al. A phase I and pharmacokinetic study of pegylated camptothecin as a 1-hour infusion every 3 weeks in patients with advanced solid malignancies. J Clin Oncol. 2003;21: 148-57.

139. Sapra P, Zhao H, Mehlig M, Malaby J, Kraft P, Longley C, et al. Novel delivery of SN38 markedly inhibits tumor growth in xenografts, including a camptothecin-11refractory model. Clin Cancer Res. 2008;14:1888-96.
140. NektarTherapeutics. Study to Evaluate the Safety and Efficacy of NKTR-102 (PEGIrinotecan) in Patients With Metastatic or Locally Advanced Breast Cancer. Clinical Trials.gov web site 2008 [online], http://clinicaltrials.gov/ct2/show/NCT00802945

141. Gradishar WJ. Albumin-bound nanoparticle paclitaxel. Clin Adv Hematol Oncol. 2005;3:348-9.

142. Gradishar WJ. Albumin-bound paclitaxel: a next-generation taxane. Expert Opin Pharmacother. 2006;7:1041-53.

143. Yoo HS, Park TG. Folate-receptor-targeted delivery of doxorubicin nano-aggregates stabilized by doxorubicin-PEG-folate conjugate. J Control Release. 2004;100:247-56.

144. Nasongkla N, Shuai X, Ai H, Weinberg BD, Pink J, Boothman DA, et al. cRGDfunctionalized polymer micelles for targeted doxorubicin delivery. Angew Chem Int Ed Engl. 2004;43:6323-7.

145. Torchilin VP, Lukyanov AN, Gao Z, Papahadjopoulos-Sternberg B. Immunomicelles: targeted pharmaceutical carriers for poorly soluble drugs. Proc Natl Acad Sci U S A. 2003;100:6039-44.

146. Jeong YI, Seo SJ, Park IK, Lee HC, Kang IC, Akaike T, et al. Cellular recognition of paclitaxel-loaded polymeric nanoparticles composed of polylgamma-benzyl Lglutamate) and poly(ethylene glycol) diblock copolymer endcapped with galactose moiety. Int J Pharm. 2005;296:151-61. 